\title{
EBSD and TEM Analysis of the Heat Affected Zone of Laser Welded AISI 304/308 Stainless Steel
}

Keyou Mao ${ }^{1}$, Yaqiao $\mathrm{Wu}^{2}$, 3, and Janelle P. Wharry ${ }^{1}$

1. School of Nuclear Engineering, Purdue University, 400 Central Dr., West Lafayette, IN 47907, USA.

2. Microscopy and Characterization Suite, Center for Advanced Energy Studies, 995 University Blvd., Idaho Falls, ID 83401, USA.

3. Micron School of Materials Science and Engineering, Boise State University, 1910 University Dr., Boise, ID 83725, USA.

The objective of this study is to utilize a range of advanced microscopy techniques to characterize the heat affected zone (HAZ) of an AISI 304 stainless steel (SS) laser weld. Laser weldments of 304 SS, made with Type 308 SS as a filler material, are of interest to the nuclear power industry because of its low energy input as compared to conventional welding techniques. Laser welds are especially relevant for mid-life weld repairs of light water reactor (LWR) internals, which contain helium, irradiationinduced voids, and other irradiated microstructural phenomena [1]. Conventional welding processes such as gas tungsten arc welding (GTAW) introduce thermal stresses, which leads to the formation of helium bubbles on the grain boundaries [2]. This phenomenon directly results in disastrous heliuminduced cracking on the weld boundary. Laser welding, however, is hypothesized to reduce the helium coalescence and cracking at the weld boundary, due to the reduced heat input that inhibits surface cracking and subsurface defects [3]. Nevertheless, no studies have characterized the laser welded microstructures at resolutions greater than scanning electron microscopy (SEM) level resolution. In this work, we utilize a combination of SEM and transmission electron microscopy (TEM) to understand the laser welded microstructure of a laser weld on unirradiated and irradiated 304 SS.

Electron backscatter diffraction (EBSD) in a SEM is utilized to investigate the grain structure of the welded sample across all three regions of the weldment: the base metal, HAZ, and filler metal. A full EBSD scan on the welded sample from the base through HAZ to the filler was performed. The results show a well-defined transition in the grain orientation and grain size from the base metal to the HAZ to the filler metal. Representative EBSD grain orientation maps from each of these regions are given in Figure 1 . The average grain size of the HAZ $(8.63 \mu \mathrm{m})$ is smaller than the grains in the base $(12.09 \mu \mathrm{m})$ and filler $(10.92 \mu \mathrm{m})$ metal. The finer grains in the HAZ are evident from the EBSD scans. The size of the HAZ is estimated to be around $3 \mathrm{~mm}$. The grain orientation angle exhibits relatively average variation in each region, suggesting no notable texturing or alignment due to the welding process.

The HAZ created by laser fusion, and the base and weld metals, all merit further characterization to investigate the microstructural effects of laser welding. TEM analysis is performed on each zone to characterize dislocation densities, precipitates and second phases, and any irradiation-induced microstructural features. The TEM lamellae are obtained utilizing the Focused Ion Beam (FIB) lift-out technique. The dimensions of each lamella are approximately $10 \mu \mathrm{m} \times 8 \mu \mathrm{m} \times 150 \mathrm{~nm}$.

Figure 2 shows TEM bright field images and the corresponding convergent beam electron diffraction (CBED) patterns from lamellae obtained from the HAZ in the unirradiated 304 SS. The brighter spots (marked by red lines) in the bright field images indicate Z-contrast due to different elemental species present in the corresponding areas, suggesting possible precipitates formed during the laser welding. 
Note that no such precipitates either are found in the base metal or weld metal TEM lamellae. From the energy-dispersive X-ray spectroscopy (EDX), these two regions have higher concentrations of $\mathrm{Cr}, \mathrm{Si}, \mathrm{O}$, and $\mathrm{C}$, and lower concentration of $\mathrm{Fe}$, as compared to the matrix. In total, three such precipitates are identified in the lamellae studied, and they have an average size of $302 \mathrm{~nm}$ at a number density of $2.5 \times 10^{17} \mathrm{~m}^{-3}$. However, the CBED does not show any diffraction pattern of these precipitates, demonstrating the amorphous nature of these precipitations that form during the laser welding process. Extensive amorphous Mn-Si precipitation was reported during laser surface melting and alloying of type 304L SS [4], but more efforts are needed to explain these non-crystalline structures.

This study on the unirradiated material will facilitate an understanding of the microstructures produced by laser welding, particularly in the HAZ, and may reveal underlying physics of the formation of the amorphous precipitation. Welds of irradiated material will enable further investigation of helium cracking mechanisms; these results are not yet available, but will be presented at the conference.

\section{References:}

[1] K. Asano et al, Journal of Nuclear Materials 264 (1999), p. 1-9.

[2] F. Garner et al, Fontevraud 8 - Contribution of Materials Investigations and Operating Experience to LWRs’ Safety, Performance and Reliability (2014) p. 27.

[3] S. Kawano et al, Journal of Nuclear Materials 258 (1998), p. 2018-2022.

[4] O. V. Akgun and O. T. Inal, Journal of Material Science 30 (1995), p. 6097-6104.

[5] The authors acknowledge funding from the Department of Energy Office of Nuclear Energy, contract DE-NE0008525, J. Tatman from the Electric Power Research Institute for the specimens, and A. Bateman and J. Burns from the Center for Advanced Energy Studies for their many useful discussions and assistance with microscopy.

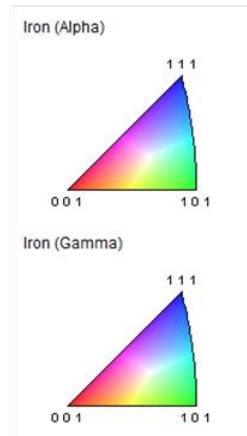

Base

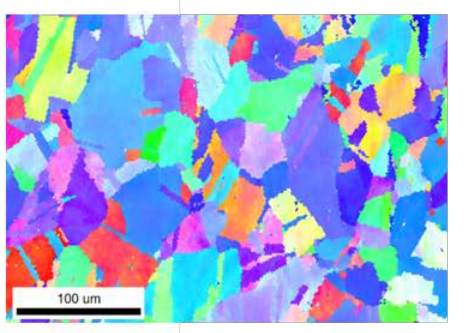

HAZ

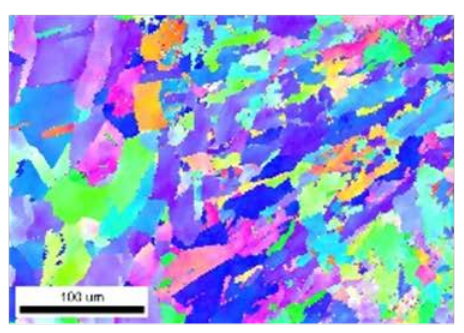

Filler

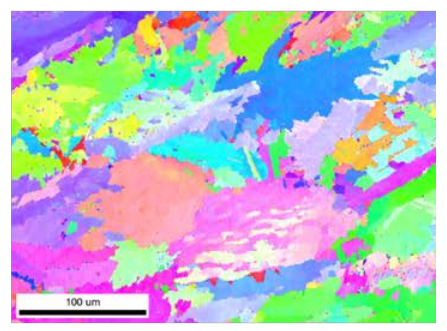

Figure 1. Representative EBSD grain orientation maps of the laser-welded sample from the base metal, HAZ, and filler metal.

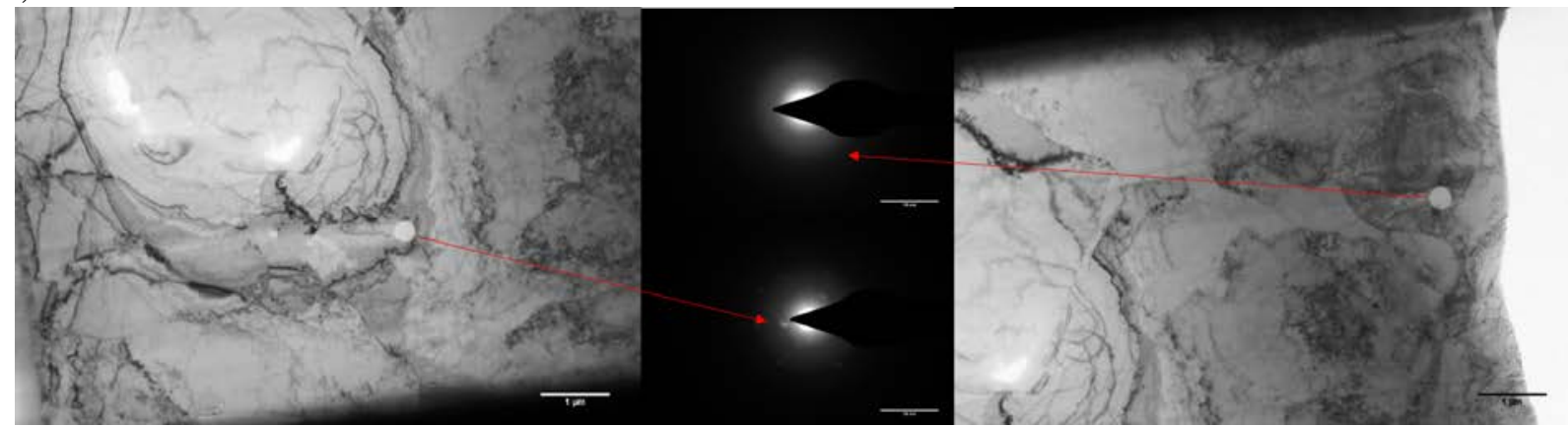

Figure 2. TEM bright field images (left and right) of the HAZ, with CBED diffraction pattern of precipitations (middle), from the unirradiated laser-welded sample at different locations. 